\title{
Supporting Indigenous Students in Science and STEM Education: A Systematic Review
}

\author{
Qingna Jin 10
}

Citation: Jin, Q. Supporting Indigenous Students in Science and STEM Education: A Systematic Review. Educ. Sci. 2021, 11, 555. https://doi.org/10.3390/ educsci11090555

Academic Editor: Ismo T. Koponen

Received: 13 August 2021

Accepted: 15 September 2021

Published: 17 September 2021

Publisher's Note: MDPI stays neutra with regard to jurisdictional claims in published maps and institutional affiliations.

Copyright: (C) 2021 by the author. Licensee MDPI, Basel, Switzerland. This article is an open access article distributed under the terms and conditions of the Creative Commons Attribution (CC BY) license (https:/ / creativecommons.org/licenses/by/ $4.0 /)$.
Department of Elementary Education, University of Alberta, Edmonton, AB T6G 2G5, Canada; qingna.jin@ualberta.ca

\begin{abstract}
There are a growing number of education programs in science and STEM education with the aim of improving educational outcomes for Indigenous students who have long been underrepresented in current education systems. The aim of this study is to systematically review empirical research from 2011 to 2020 that reported programs to support Indigenous students in science and STEM education. A total of 24 studies were included in this review. These programs involved student participants from all $\mathrm{K}$ to 12 grade levels and occurred in both formal and informal contexts. Most of the programs employed multifaced approaches, and cultural relevance and scientific inquiry practice were the two main features of the programs. All the programs had reported positive outcomes in relation to Indigenous students' science learning, understanding of their own cultures and traditions, and/or the complementarity of Western science and Indigenous knowledge.
\end{abstract}

Keywords: Indigenous students; science education; STEM education; K to 12; systematic review

\section{Introduction}

Quality education for all students, and in particular improving the educational outcomes for Indigenous students, has been a focus in many countries such as the United States, Australia, and Canada [1-5]. Despite this, there continues to be disparities between Indigenous and non-Indigenous students, especially in STEM subject areas [2,4]. Because science and STEM education focus mostly Western science knowledge to the exclusion of other ways of knowing, Indigenous worldviews are usually undermined in Indigenous students' science and STEM learning experiences, which has created tension between traditional Indigenous knowledge and school science [6]. When Indigenous students are forced to compromise their cultural identity, their science learning and development of scientific literacy are impeded. One possible way to provide Indigenous students with access to science learning without comprising their cultural identity is making science programs aligned with their traditional knowledge and everyday experiences [6]. With the aim to support educational success for Indigenous students, there are a growing number of educational programs that engage Indigenous children and youth in STEM education by integrating Indigenous knowledge with Western science to make the programs culturally responsive and relevant [7].

Recent reviews have examined how teachers' professional development, pedagogical strategies, curriculum structure, and education policies impact Indigenous students' learning experiences and academic performances [1,2,5,8-10], and suggest "the use of evidence-based research to develop, enact and evaluate future effort" to support Indigenous students [10] (p. 77). Following this recommendation and with the purpose of providing helpful information for future educational efforts, this systematic review was undertaken to research empirical practices and outcomes related to programs in science and broader STEM areas which aimed to support Indigenous students. In particular, this review sought to identify major practices and outcomes in these programs. The primary research question guiding this review was: In $\mathrm{K}$ to 12 science and STEM education, which program 
practices does the published literature suggest are linked with positive educational outcomes for Indigenous students? To address this question, this review identified intended program practices and outcomes reported in the published literature, which led to the identification of two supporting research questions: (1) In K to 12 science and STEM education, what efforts and practices have been implemented to support Indigenous students? And (2) what outcomes and associated findings have been reported in programs?

\section{Methods}

\subsection{Systematic Review Design and Search Process}

This review followed internationally recognized guidelines developed by a nonpartisan scientific body, PRISMA, which describes criteria for conducting and reporting systematic reviews [11]. To augment the PRISMA process and account for field-specific perspectives, I also incorporated techniques that social science researchers Cooper [12] and Gough et al. [13] recommended.

I used three sets of search terms in three academic databases: Academic Research Complete, Education Research Complete, and ERIC. The first set of terms identified studies focused on Indigenous students (i.e., Indigenous OR native OR aboriginal OR first nations) and the second set narrowed the scope to studies in the areas of science and STEM education (i.e., science education OR science teaching OR science learning OR STEM). These two sets of search terms were combined using the operator "AND". The third set of search terms (i.e., university OR college OR higher education) was intended to narrow the scope to studies to the $\mathrm{K}$ to 12 levels by excluding studies at the post-secondary level. Thus, it was combined with the first two sets using the operator "NOT". Other limiters were also applied to the initial search, including (1) published between 1 January 2011 and 31 December 2020; (2) peer-reviewed scholarly articles; and (3) written in English. After removing the duplicates, the initial search returned 404 total citation records.

\subsection{Study Screening and Eligibility}

A critical peer was invited to participate in the screening and assessment for eligibility for the purpose of peer-checking. To screen the 404 citation records, I, together with the critical peer, read each title and abstract to identify relevant studies based on the following inclusion criteria: (1) focused on Indigenous students; (2) reported practice and outcomes of educational programs; (3) focused on K to 12; (4) in science or STEM areas; (5) designed as empirical research or program evaluation; and (6) published in scholarly journals. Based on reviewing the titles and abstracts, 321 studies were excluded. Many of them involved learners at the post-secondary level, did not include outcomes or practice, and/or were not related to science or STEM learning. I then located the full-text versions for the remaining 83 citations. Next, the full text of these 83 articles was reviewed, focusing on eligibility for final inclusion in the review. Fifty-nine articles were excluded which did not meet the previously described first-round inclusion criteria. Upon completion of the full-text scan, 24 articles remained for inclusion in this systematic review. Figure 1 details the search and screening processes with the PRISMA Flow Diagram.

\subsection{Data Analysis}

The 24 studies were rigorously coded for analysis. To guide the data extraction, I developed a codebook that described the major coding categories of interest [14] (see Table 1). To avoid being limited by this predeveloped codebook, I used in vivo coding (i.e., extracting exact wording) when applicable [15]. This inductive technique helped capture unexpected data and led to the development of new codes [14,16]. By iteratively revising and rearranging codes, the codebook was modified based on emergent trends. For instance, in initial rounds of coding, I tried to assign codes to describe specific science subjects in which students' learning activities happened, such as biology, earth science, and chemistry. In subsequent rounds, I noticed patterns related to whether the topics that students worked 
on were related to nature and the environment. Therefore, I revised the topic/subject category to note relevance to nature and environment.

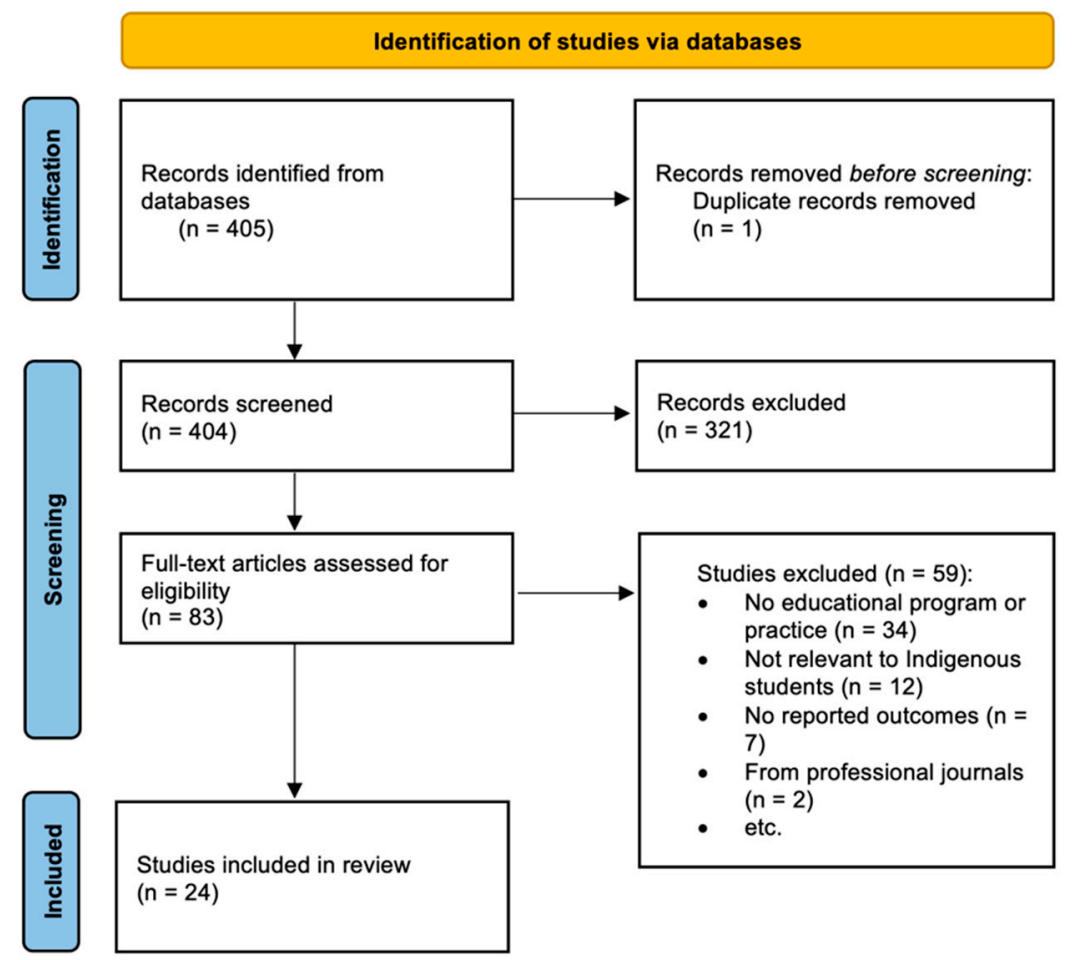

Figure 1. PRISMA flow diagram.

Table 1. Article coding.

\begin{tabular}{|c|c|c|}
\hline Coding Category & Sub-Category & Examples of the Codes \\
\hline \multirow{8}{*}{ Study characteristics } & \multirow{2}{*}{ Publication outlet } & Cultural Studies of Science Education, Journal of STEM \\
\hline & & Education, The Australian Journal of Indigenous Education \\
\hline & Publication year & $2011,2012,2013$ \\
\hline & Region & North America, Asia, Africa \\
\hline & Research desion & Case study of implementing a program or practice, \\
\hline & & Experiment design with controlled and experimental groups \\
\hline & Research method & Qualitative, Quantitative, Mixed methods \\
\hline & Program context/setting & Formal school context, Informal context \\
\hline & Program implementer(s) & $\begin{array}{l}\text { Classroom teachers; Indigenous knowledge holders, } \\
\text { Researchers, Other }\end{array}$ \\
\hline Program characteristics & Recurrence & Yearly, Not recurring \\
\hline & Length of the program & $\begin{array}{l}2 \text { weeks, } 6 \text { months, } 1 \text { semester, } 1 \text { academic year, } 1 \text { learning } \\
\text { unit, no info }\end{array}$ \\
\hline & Number of students & 26,42 , two classes, no info \\
\hline & Learning topics & Topics related to nature and/or environment, Other \\
\hline $\begin{array}{l}\text { Features of the educationa } \\
\text { practice or intervention in }\end{array}$ & $\begin{array}{l}\text { (i.e., characteristics of the } \\
\text { gram) }\end{array}$ & $\begin{array}{l}\text { Scientific inquiry, Design and making, Cultural relevance, } \\
\text { Technology involvement, Dialogical/communicative focus, } \\
\text { Multimodal practice, Literacy practice, Other }\end{array}$ \\
\hline & Overall outcomes & Positive, Negative, Null \\
\hline & & $\begin{array}{l}\text { Conceptual learning in science, Nature of science (NOS), } \\
\text { Interest in and attitudes towards science or STEM, }\end{array}$ \\
\hline Outcomes of the program & & Postsecondary education and career options, Identity as \\
\hline & Outcomes reported & science learners, Understandings of traditional Indigenous \\
\hline & & $\begin{array}{l}\text { knowledge, Interest and pride in Indigenous knowledge and } \\
\text { cultures, Connection and complementarity between science } \\
\text { and Indigenous knowledge }\end{array}$ \\
\hline
\end{tabular}


To analyze the coding results, I adopted the mixed research synthesis review approach suggested by Ardoin and Bowers [14]. Specifically, where appropriate, I used 'counting' to aggregate the data. For instance, I coded and counted the code categories for regions, student grade level(s), research methods, etc. Those descriptive statistical analyses provided a general description of the trends in the research. To analyze data on features of practices and outcomes, I employed the constant comparison approach for thematic analyses [17]. Throughout the entire analysis process, the critical peer had also been involved for peer checking.

\section{Results}

Results in this section were organized and presented in terms of the main coding categories (see in Table 1). In what follows, I first describe results related to study and program characteristics, followed by features of the program practices and reported outcomes of the programs.

\subsection{Study Characteristics}

The 24 studies included in this review were published in 17 journals. Seven studies $(29 \%)$ were published in three journals which had Indigenous and broad cultural focus (i.e., The Australian Journal of Indigenous Education, Australian Aboriginal Studies, and Cultural Studies of Science Education). Four studies (17\%) were published in journals with the environment education focus (i.e., Applied Environmental Education and Communication and Journal of Geoscience Education). In terms of single journals, Cultural Studies of Science Education, The Australian Journal of Indigenous Education, and Journal of Geoscience Education had the most studies (i.e., 3 in each of them). Within the 10-year search period, eight $(33 \%)$ studies in the reviewed samples were published in the first half of the time span (2011-2015) and 16 (67\%) were published between 2016 and 2020.

In terms of geographic distribution, North America was the most heavily represented with $11(46 \%)$ programs occurring in the United States and two studies (8\%) in Canada. Australasia was heavily represented in the sample as well with five studies $(21 \%)$ highlighting programs in Australia. The other six studies reported on programs in Asia (three studies, $13 \%$ ), Africa (two studies, $8 \%$ ), and South America (one study, $4 \%$ ).

Of the 24 studies included in this review, $16(67 \%)$ were coded as focused on qualitative data. These studies primarily employed interview and observation as methods to collect qualitative data on Indigenous students' experiences. The other eight studies (33\%) used a mixed methods approach to produce both qualitative and quantitative data. Survey and test results were the main sources for quantitative data in these studies. In terms of the research design, 23 studies (96\%) were designed as case studies reporting the design, implementation, and outcomes of educational programs. Only one study $(4 \%)$ used quasiexperimental design to evaluate the effectiveness of an intervention by comparing students performances in controlled and experimental groups. See Figure 2 for a summary of study characteristics.

\subsection{Program Characteristics}

Of the 24 studies included in this review, 11 studies (46\%) were about programs in informal contexts (e.g., community centers and outdoor settings), 11 studies (46\%) reported practice that occurred in a formal school context and during school time, and two studies $(8 \%)$ reported programs that involved both formal and informal settings. See Figure 3 for a summary of program characteristics. Programs in different settings had different patterns in terms of characteristics, such as whether Indigenous knowledge holders were involved in program implementation, or whether the programs were recurrent (see Figure 3). Thus, in what follows, characteristics of programs in informal, formal, and both settings were described separately. 


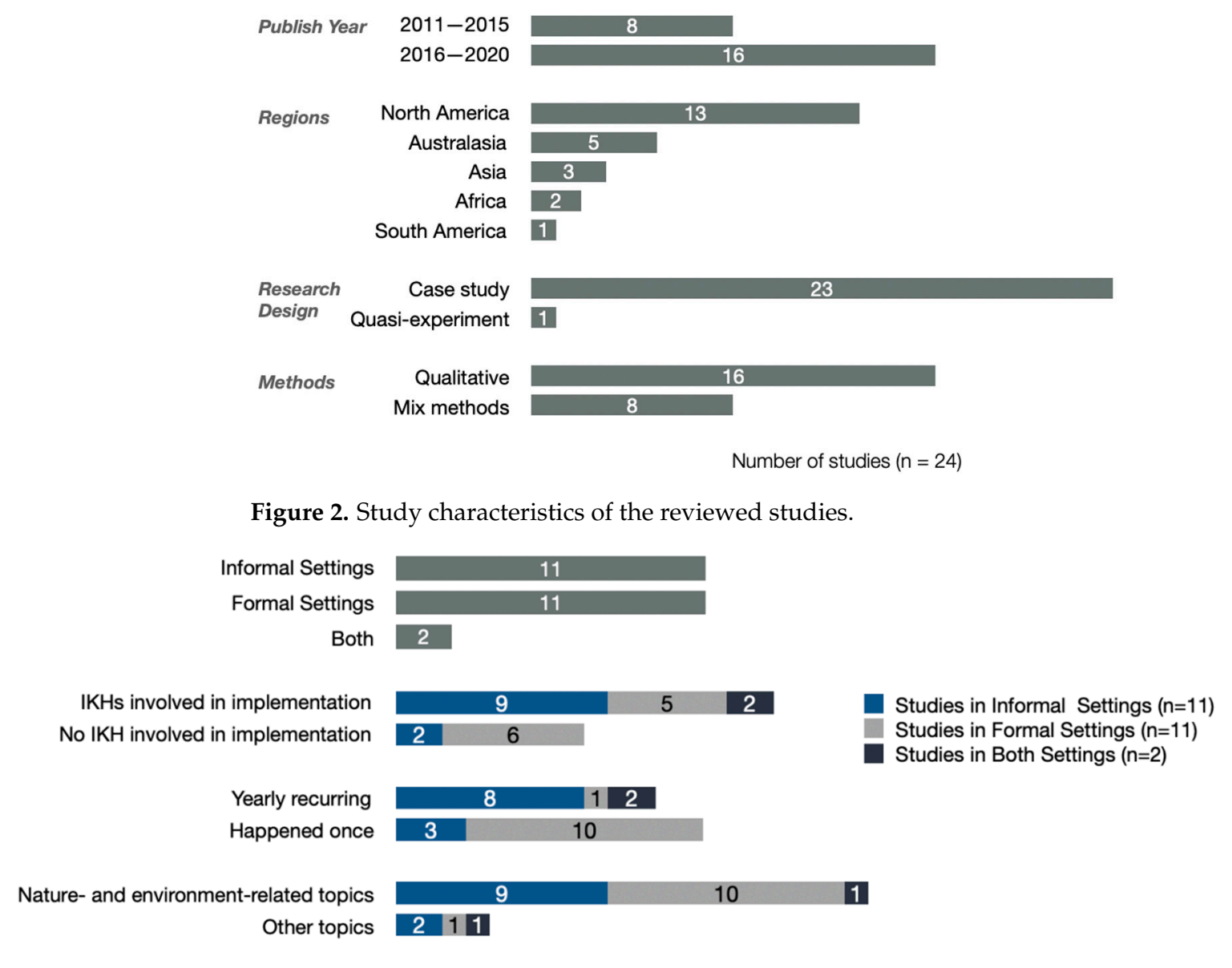

Number of studies $(n=24)$

Figure 3. Program characteristics of the reviewed studies.

\subsubsection{Programs in Informal Settings}

Programs that occurred in informal settings usually had people from multiple groups involved in the program implementation, such as researchers in education, Indigenous knowledge holders, and/or staff from related institutions. Of these 11 programs, the majority $(\mathrm{n}=9,82 \%)$ had Indigenous knowledge holders, including elders, artists and/or storytellers from Indigenous communities, involved in the program design and implementation. For instance, in Barajas-López and Bang [18] and Kellogg et al. [19], Indigenous knowledge holders guided students outdoor fieldworks; people from Indigenous communities designed and led workshops on traditional cultural activities in Tzou et al. [20] and Eglash et al. [21]; in Barajas-López and Bang [18] and Pugh et al. [22], Indigenous knowledge holders communicated and connected with students via storytelling. In the other two programs (18\%), Indigenous knowledge holders were not directly involved in implementation. One [23] emphasized that all mentors in the program (i.e., implementors of the program) had a long association with the Indigenous community where the student participants came from, and thus were familiar with students' Indigenous culture. In the other program [24], instead of the program implementation, Indigenous knowledge holders were involved at the evaluation stage to assess the cultural merit of students' work. (See Figure 3 for a summary of program characteristics.)

Among the 11 programs that occurred in informal settings, the majority $(\mathrm{n}=8,73 \%)$ were programs recurring every year, such as Guzey et al. [25] and Pugh et al. [22], and three programs (27\%) happened only once, such as Tzou et al. [20] and Eglash et al. [21]. As of the time the articles were written, seven yearly programs had been implemented for three to five years and one had been implemented for more than ten years. Of these 11 programs 
in informal contexts, nine occurred during the summertime as summer camps or summer programs with different lengths ranging from two days to two weeks. (The length was based on the available information found in the articles, although some articles only mentioned that the program was a summer camp without providing specific information about the length).

Students who participated in these informal programs ranged from six years of age to those in the twelfth grade. These programs usually had students from multiple grade levels learning together. The number of students being involved in each program varied from three to more than a hundred. With the exception of two programs in which students experienced Indigenous artwork and technology-supported diorama building and storytelling $[20,21]$, all these informal programs provided students with topics that were related to nature and the environment, exploring local ecosystems, natural resources management, medicinal plants, and human health, etc. Examples include Guzey et al. [25], Ricci and Riggs [26], Cheeptham et al. [27], and Pugh et al. [22].

\subsubsection{Practice in Formal School Settings}

Of the 11 practices in a formal classroom context, around half $(n=5,45 \%)$ were implemented solely by school science teachers. One was an Indigenous teacher's action research in her own classroom. In this article, Shortland and Locke [28] reported that an Indigenous science teacher used creative narratives with her high school students as a way of developing their understanding of the human digestive system. The other four were implemented by non-Indigenous teachers such as Lee et al. [29]. Another five practices $(45 \%$, of 11$)$ were implemented by science teachers in collaboration with Indigenous knowledge holders, such as elders and other members from Indigenous communities. Usually, in these programs, such as Rioux et al. [30,31], Sánchez Tapia et al. [6], teachers and these Indigenous knowledge holders worked together on integrating Indigenous knowledge into science curricula. In some cases, Indigenous knowledge holders also guided students' culturally related activities, offered lectures on cultural traditions, and interacted with students via storytelling. It is noteworthy that, among these 10 studies in which schoolteachers were involved in the practice implementation either solely or in collaboration with Indigenous knowledge holders, only two of them explicitly stated that teachers were provided with professional support on culturally responsive pedagogy. Except for these practices that were implemented by teachers, there was one program which took place in schools yet was conducted by presenters from a not-for-profit organization. In the article [32], it was emphasized that all the presenters had backgrounds in science and had been trained in terms of how to interact with Indigenous students. This was the only program that was recurring every year and taking place in multiple schools at the same time.

Of the 11 practices in school settings, four (36\%) were at elementary levels, and seven $(64 \%)$ were in middle and high schools. Six studies (54\%) involved only one grade, with students from one or two classes, three studies $(27 \%)$ had student participants from multiple grades (e.g., grade 4 to 6), and two studies (18\%) did not provide specific information. The number of students being involved in these classroom practices ranged from ten to more than a hundred. Compared with informal programs, practices in formal classrooms were relatively longer, ranging from a learning unit spanning several weeks to an academic year. Similar to the informal programs, during the formal classroom practices, students usually worked on nature- and environment-related topics. Only one study [33] was on classroom practice about an Indigenous traditional festival.

\subsubsection{Programs Involving Both Formal and Informal Contexts}

Of the 24 studies included in this review, two studies, Anthony-Stevens et al. [34] and Miller and Roehrig [35], reported hybrid programs that occurred in both formal school contexts (i.e., in-school activities) and out-of-school informal settings (i.e., field trip). Both these programs had Indigenous knowledge keepers participating in the implementation as mentors guiding students' field trips. In one program, students experienced and reflected on 
a traditional outdoor game for 12 weeks [35]. The other program engaged students in exploring topics related to local ecosystems, such as watershed and solar energy, for an academic year [34]. Both programs happened every year and incorporated technologies to support students' learning. In terms of the student participants, both programs had students from multiple grades from upper elementary to middle school levels.

\subsection{Features of the Program Practice}

Analysis of features of the practices mainly focused on what measures or interventions were implemented to support Indigenous students in $\mathrm{K}$ to 12 science and STEM education. Eight categories were identified which are explained below in Table 2. These coding categories were not exclusive; thus, a single study could have multiple codes as they were all applicable.

Table 2. Features of the Program Practice.

\begin{tabular}{|c|c|}
\hline Program Feature Category & Explanation \\
\hline Scientific inquiry & $\begin{array}{l}\text { Engaging students in scientific inquiry using (Western) science methods for doing } \\
\text { scientific investigation, such as formulating hypotheses and collecting data by } \\
\text { designing and doing experiments }\end{array}$ \\
\hline Design and making & $\begin{array}{l}\text { Engaging students in hands-on design and making, such as building dioramas, } \\
\text { models, and devices }\end{array}$ \\
\hline Cultural relevance & $\begin{array}{l}\text { Emphasizing Indigenous knowledge, Indigenous ways of knowing, connections to } \\
\text { the local communities, etc. }\end{array}$ \\
\hline Technology involvement & $\begin{array}{l}\text { Providing students with opportunities to interact with digital technologies, such as } \\
\text { using software for computer simulation, using GIS for geo-information collection } \\
\text { and analysis, using online platforms for communication }\end{array}$ \\
\hline Dialogical/communicative focus & $\begin{array}{l}\text { Engaging students in collaborative group work with the dialogical or } \\
\text { communicative focus, providing students with opportunities to communicate and } \\
\text { discuss with peers }\end{array}$ \\
\hline Multimodal practice & $\begin{array}{l}\text { Either the instruction was communicated/implemented multimodally or by } \\
\text { engaging students in multimodal practice }\end{array}$ \\
\hline Literacy practice & $\begin{array}{l}\text { Focus on literacy practice, such as (scientific) vocabulary building, narrative } \\
\text { writing, creative writing, and students' storytelling }\end{array}$ \\
\hline Others & Others not included in the above categories \\
\hline
\end{tabular}

All but one of the programs have multiple features in terms of approaches they adopted. One quasi-experimental study [36] reported the impact of dialogical argumentation instructional strategy on Indigenous students' science learning by comparing students' performances in the experimental and controlled groups. This study was assigned only one code (i.e., dialogical/communicative focus). All of the other 23 studies had two or more codes as approaches in these programs were multifaceted. Figure 4 below shows the features of the programs reviewed in this study.

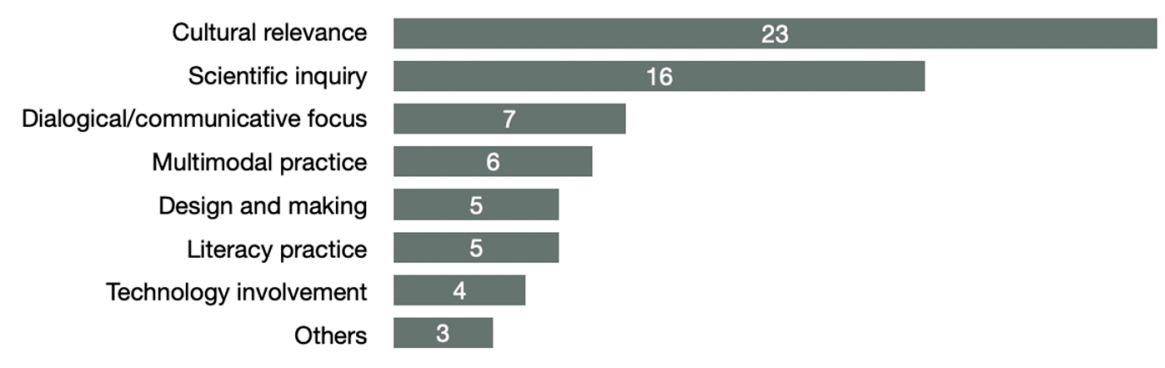

Number of studies $(n=24)$

Figure 4. Features of the program practice.

Two features, cultural relevance and scientific inquiry, were evident in the analysis. Of the 24 studies included in this review, 23 (96\%) had Indigenous knowledge and/or 
ways of knowing integrated in students' science or STEM learning, which made the programs culturally relevant to Indigenous students. In some cases, such as Pugh et al. [22] and Barajas-López and Bang [18], students learned and experienced Indigenous ways of knowing, including respect for the land, and reciprocal relationships with the environment and others. In other cases, student learning was embedded in the context of traditions and stories of Indigenous tribes, such as traditional festivals [33] and cultural activities [35]. There were also programs, such as Karagatzides et al. [23], that engaged students in investigation of issues faced by the local Indigenous communities (e.g., management of natural resources).

Two thirds of the programs (16 out of 24 ) emphasized scientific inquiry during the program implementation. In these programs, such as Guzey et al. [25], Cheeptham et al. [27], and Kellogg et al. [19], students were provided with opportunities to experience and practice the disciplinary norms and ways of knowing employed by scientists or engineers as they construct, evaluate, communicate, and reason with knowledge to explain, predict, and describe phenomena.

In addition to cultural relevance and scientific inquiry, there were some other features identified. Of the 24 programs, seven (29\%) had a dialogical/communicative focus. In these programs, such as Ricci and Riggs [26], Karagatzides et al. [23], and Hackling et al. [32], emphasis were placed on students' group work to facilitate students' communication and collaboration with peers for the purpose of sense-making and problem-solving. 6 programs (25\%) emphasized multimodal practice. In these programs, either the instructions and explanations were communicated multimodally to reduce the reliance on spoken words by incorporating gestural, visual, and audio elements [32], or students' activities were multimodal as they experienced and interacted with multimodal representations, such as taking notes by writing, drawing, and taking photos while walking in outdoor environments to observe medicinal plants [21]. Five studies (21\%) placed emphases on engaging Indigenous students in hands-on design and making. For instance, students in Tzou et al. [20] were encouraged to build dioramas with everyday common materials to tell stories of their Indigenous identities. In another program (Guzey et al. [25]), students designed and built devices to catch and store wind energy with the aim to solve the energy issues faced by their local community. Also, five studies (21\%) focused on students' literacy practice, such as teaching and engaging students in creative and narrative writing and storytelling [28], and assisting students in building and using science disciplinary vocabularies [32]. Involvement of technology was emphasized in four studies (17\%). In these programs, students either used technology tools (e.g., Google Earth, GIS, design software programs, or coding applications) for their own projects $[25,34]$ or participated in the program in an online learning environment [35]. Three studies (13\%) were assigned with the code others because they had features which were not included in these aforementioned categories. These features were intergenerational collaboration [20], sociopolitical perspective [37], and relationship building with the mentors [34].

\subsection{Reported Outcomes}

All the 24 studies included in this review reported positive outcomes in terms of the influence of the designed programs on Indigenous students. Reviewing these outcomes identified eight categories, which are explained in detail in Table 3 below. The first five categories, conceptual learning in science, nature of science (NOS), interest in and attitudes towards science or STEM, postsecondary education and career options, identity as science learners, were science-related outcomes (category I as shown in Table 3); the following two, understandings of traditional Indigenous knowledge and interest and pride of Indigenous knowledge and culture, were about Indigenous knowledge and cultures (category II), and the last one was about connections and complementarity between science and Indigenous knowledge (category III). These coding categories were also not exclusive. 
Table 3. Outcomes reported in the studies.

\begin{tabular}{|c|c|c|}
\hline Outcome Category & Sub-Category & Explanation \\
\hline \multirow{5}{*}{ I: Science-related Outcomes } & Conceptual learning in science & $\begin{array}{l}\text { Development of scientific knowledge and } \\
\text { understandings, and development of procedural } \\
\text { knowledge and skills of scientific inquiry }\end{array}$ \\
\hline & Nature of science (NOS) & Development of understandings of NOS \\
\hline & $\begin{array}{l}\text { Interest in and attitudes towards } \\
\text { science or STEM }\end{array}$ & $\begin{array}{l}\text { Development of interests in and positive attitudes } \\
\text { towards science and other STEM subjects }\end{array}$ \\
\hline & $\begin{array}{l}\text { Postsecondary education and career } \\
\text { options }\end{array}$ & $\begin{array}{l}\text { Willingness to pursue a postsecondary education } \\
\text { and/or a career in science or STEM areas }\end{array}$ \\
\hline & Identity as science learners & $\begin{array}{l}\text { Construction of identity as science learners through } \\
\text { such as building confidence in learning science }\end{array}$ \\
\hline & Understandings of traditional & Development of understandings of Indigenous \\
\hline II: Indigenous culture-related & Indigenous knowledge & knowledge and their own traditional cultures \\
\hline Outcomes & $\begin{array}{l}\text { Interest and pride in Indigenous } \\
\text { knowledge and cultures }\end{array}$ & $\begin{array}{l}\text { Interest in, pride of, and appreciation of their own } \\
\text { traditional cultures }\end{array}$ \\
\hline $\begin{array}{l}\text { III: Outcomes related to the } \\
\text { complementarity }\end{array}$ & $\begin{array}{l}\text { Connection and complementarity } \\
\text { between science and Indigenous } \\
\text { knowledge }\end{array}$ & $\begin{array}{l}\text { Awareness and appreciation of the connection and } \\
\text { complementarity between the two knowledge } \\
\text { systems: Western science knowledge and } \\
\text { Indigenous knowledge }\end{array}$ \\
\hline
\end{tabular}

As shown below in Figure 5, of the 24 studies included in this review, 21 (88\%) measured and reported outcomes related to Indigenous students' relationship with science, including science learning, science-related careers, and attitudes toward science. 11 studies (46\%) presented outcomes related to Indigenous students' relationship with their own cultures and traditional knowledge, including understandings and pride of Indigenous knowledge and traditions. 6 studies (25\%) reported outcomes around Indigenous students' awareness and perceptions of the connections between Western science and Indigenous cultures.

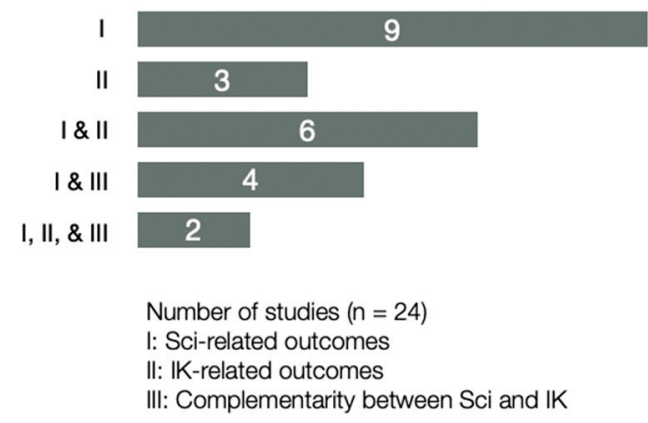

Figure 5. Outcomes reported in studies (broad categories).

\subsubsection{Supporting Indigenous Students' Science Learning}

Many of the studies included in this review aimed to support Indigenous students' learning and future careers in science and the broader STEM areas. In these studies, outcomes related to science were evaluated and reported, which mainly clustered around conceptual learning in science ( $\mathrm{n}=10,42 \%)$ and science identity construction $(\mathrm{n}=10,42 \%)$ (see Figure 6). Some studies, such as Guzey et al. [25] and Kellogg et al. [19], reported improvements of Indigenous students' conceptual learning in science, including development of scientific knowledge around topics such as ecosystems, energy, and plants, and procedural knowledge and skills of doing science, such as knowledge and skills of designing and performing scientific experiments by controlling variables. By improving Indigenous students' confidence and self-efficacy of learning science and using science in their daily lives, programs such as Miller and Roehrig [35] and Dublin et al. [24] facilitated the construction of Indigenous students' identities as 'science learners', 'science users' and 'emerging scientists' and expanded their agency in science and STEM. In these programs, 
indigenous students recognized their own and peers' competences to do science, as well as the capitals they hold which can be accessed to support their science learning.

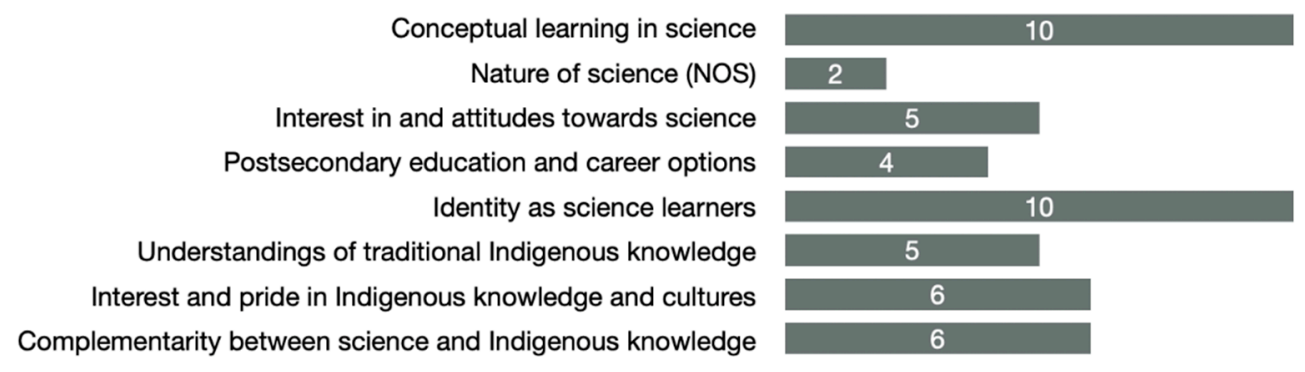

Number of studies $(n=24)$

Figure 6. Outcomes reported in studies.

Five studies (21\%) presented how the programs improved Indigenous students' interests in science and fostered their positive attitudes towards science, such as AnthonyStevens et al. [34] and Hackling et al. [32]. Four studies (17\%) reported programs' positive impact on Indigenous students' preferences toward science or STEM careers and pursuing STEM in their future post-secondary education $[27,38]$. The nature of science (NOS) was also addressed in two studies $(8 \%)[36,37]$. Participating in these programs, Indigenous students realized the links between science and its social contexts, that is, the social embeddedness in science which is an important aspect of NOS [39].

3.4.2. Indigenous Students' Understandings of and Attitudes towards Their Own Cultures and Traditions

Some programs reviewed in this study were designed and implemented with the goal of Indigenous resurgence and cultural flourishing. Five programs $(21 \%)$, such as Tzou et al. [20], Eglash et al. [21], and Pugh et al. [22], supported Indigenous students' understanding of their own cultures and traditions. Outdoor activities and cultural practice in these programs provided Indigenous students with opportunities to explore natureculture relations and thus deepened their understandings of their own cultures. Six studies (25\%), such as Lee et al. [29], Rioux et al. [30,31], and Chiang and Lee [33], reported that Indigenous students increased interest and pride in their heritage and culture knowledge. By interrelating with stories and traditional activities (e.g., festivals and ceremonies) in these programs, Indigenous youths strengthened connections to their communities, cultural inheritance, and Indigenous worldviews, and thus became prouder of their cultures and Indigenous personal identities.

3.4.3. Indigenous Students' Appreciation of the Connection between Science and Indigenous Knowledge

Six studies (25\%) reported that, by participating in these programs, Indigenous students realized the benefits of the co-existence between science and Indigenous ways of knowing. For instance, they shared that "they can live a cultural way of life and sill be scientists" [26] (p. 487). Indigenous students involved in these programs valued the Indigenous knowledge embedded science curriculum, were motivated to seek out both cultural stories and scientific information to broaden their knowledge, and enjoyed learning science from an Indigenous cultural perspective $[25,26,40]$. Based on the reported results, it is evident that students recognized and appreciated that these programs invited multiple perspectives, including scientific and Indigenous ways of knowing, to build a rich tapestry of understanding about natural phenomena.

\section{Discussion}

Indigenous students' science and STEM learning experiences have received increasing attention. Thus, the number of relevant studies has gradually risen within last decade. 
This study systematically reviewed educational programs which aimed to support Indigenous students in science and STEM areas in the last ten years. These programs covered all the grade levels from elementary to high school and all had reported positive outcomes. In this section, I synthesize results of this review and discuss resulting trends and implications emerging from that synthesis, with the emphasis on relevance to researchers and practitioners who are working towards education equity for Indigenous students.

\subsection{Formal and Informal Contexts}

Programs reviewed in this study involved both informal and formal school contexts. Informal science and STEM education which allows for flexibility and creativity that is not always possible in a formal classroom setting has the potential to provide educational experiences that lead to further interest and enjoyment of science and a sense that science learning can be personally relevant [41]. Therefore, it is not surprising to find that around half of the programs reviewed in this study took place in informal contexts. This also echoes what was suggested in the literature- that there is a growing trend to design informal afterschool and summer programs that use traditional Indigenous knowledge to engage children and youth in science and STEM [7]. Formal education, especially formal mainstream science education, has been criticized for failing to incorporate multiple epistemologies and ways of knowing [7,42,43]. Nevertheless, around half of the studies ( $\mathrm{n}=11,46 \%)$ included in this review reported positive outcomes of practices occurring in formal science classrooms. These findings suggest the possibilities and fruitfulness of formal schooling to supporting Indigenous students by integrating Indigenous knowledge into school science curricula.

\subsection{Underrepresentation of Indigenous Teachers \& Limited Support for Non-Indigenous Teachers}

It is concerning to find that, of the 24 studies included in this review, very few were designed and/or implemented by Indigenous teachers. Despite researchers and Indigenous members having long argued that Indigenous teacher programs are critical to meet to need of Indigenous children and youth "who have experienced over a century of colonization, ethnocide, and linguicide perpetuated through the public schooling", the underrepresentation of Indigenous teachers in education system is still obvious and thus requires attention [34] (p. 544). Moreover, among the studies reviewed in this study, few of them explicitly described non-Indigenous teachers had received professional support regarding culturally responsive pedagogy. (This is based on the information included in the articles. I acknowledge that it is possible that other programs also provided nonIndigenous teachers with professional support but did not describe this explicitly in the articles.) Schoolteachers have significant influential impact on Indigenous children's learning [44]. Therefore, for the well-being of Indigenous students, it is necessary to provide their non-Indigenous teachers with opportunities to develop knowledge, skills, and perspectives that enable them to understand their students' lives in context $[45,46]$. It is conjectured, based on results of this review, that non-Indigenous teachers still do not have sufficient support to prepare them for teaching Indigenous students. This echoes Ma Rhea, who have argued that it is one of the most "pressing issues" that few non-Indigenous teachers have had the opportunity to engage with sustained Indigenous studies to develop their pedagogical content knowledge [47] (p. 117).

\subsection{Cultual Relevance and Scientific Inquiry: Main Feasures of the Programs}

In science education, a strong emphasis has been placed on cultural assets and cultural context as important aspects of equity [48]. To support Indigenous students in science and STEM areas, scholars argue that educational efforts must value students' cultural backgrounds and lived reality $[49,50]$ and help them navigate between the culture of their everyday life and the culture and accepted practices of Western modern science [24,51]. Culturally responsive science education is suggested as an approach that supports Indigenous students in crossing boundaries between their Indigenous cultures, traditional knowledge, 
and Indigenous ways of knowing, and the practices and knowledge of science [24,51-53]. Results from this review echo this suggestion in the literature. Almost all the programs reviewed in this study had 'cultural relevance' as their main feature. Indigenous cultural aspects including traditional knowledge and ways of knowing were integrated in these programs. In the programs, students participated in traditional activities and ceremonies [33,35], experienced storytelling and creating their own stories [20,22], and explored issues that were faced by their communities $[23,25]$. Based on the outcomes reported in these studies, those culturally relevant practices helped connect students' educational experiences to their own lived reality and cultural identities. Instead of putting Indigenous knowledge and Western science knowledge in opposition to one another, these culturally relevant programs extend knowledge systems and find value and new perspectives for teaching and learning from both [7]. In this way, students' cultures are respected and valued as resources for learning. In addition, Indigenous people had broad involvement in these programs, which also helped make these programs culturally relevant to Indigenous students. This is consistent with the recommendation from Gillan et al. [10] that Indigenous people should be involved, especially in decision-making roles, to help shape and encourage support for initiatives to promote educational success for Indigenous learners.

Results of this study showed that inquiry-based science practice was widely used in these programs (16 out of 24 ) to engage Indigenous students, such as obtaining, evaluating, and communicating information or evidence, constructing scientific explanations and designing solutions, and developing and using models. Programs like these that focused on science inquiry reported positive outcomes. This is consistent with results from another review, in which Brown [8] identified several areas of complementarity between culturally responsive and inquiry-based science practices. These results from both this study and others in the literature have clear implications in the field that could advance Meyer and Crawfold's [54] call to make inquiry-based science intentionally culturally responsive.

\subsection{For Diversity of STEM and/or for Indigenous Resurgence}

Programs reviewed in this study measured and reported different aspects of students developments. Three broad outcome categories were identified in this review: (1) outcomes related to Western science or STEM; (2) outcomes related to Indigenous knowledge and culture; and (3) outcomes related to the complementarity between Western science and Indigenous science. (Table 3 includes detailed explanations.) Some programs focused mainly on science- or STEM-related outcomes, such as development of scientific knowledge, increased interest in science and STEM, and enhanced identity of science learners. It is conjectured that the integration of Indigenous knowledge (e.g., Indigenous stories, examples, and contexts) in these programs is mainly to make Western science more relevant to Indigenous students and, thus, to attract more Indigenous students into STEM fields to increase the diversity of STEM areas. McKinley and her colleagues call this type of integration "bicultural science education" [55] (p. 583). Though this bicultural science education attempts to increase the self-esteem of Indigenous students by placing value on their cultures, it maintains the science programs' Western framework as a basis for instruction and fails to establish an Indigenous framework for instruction. Therefore, it was criticized by many scholars [53,55]. Instead, Aikenhead [53] proposed a "cross-cultural" approach, one which "gave students access to Western science and technology without requiring them to adopt the worldview endemic to Western science, and without requiring them to change their own cultural identity" (p. 349). Programs which had outcomes falling in multiple categories (e.g., students developed their scientific knowledge as well as understandings of their own traditional cultures) are consistent with this approach These programs have the potential to provide students who are interested in Western science with the foundation and encouragement for further study and career options in science and STEM areas. For other students, these programs help identify two cultures, the culture of their Indigenous community and the culture of Western science and STEM, and "help students feel at ease in both cultures and help students move back and forth 
between the two cultures" [53] (p. 349). In this way, these programs contribute to both the diversity of STEM and Indigenous resurgence.

\section{Final Thoughts}

Studies included in this review were limited to ones that were published in scholarly journals. There are many other programs which did not share their practices or outcomes by publishing scholarly articles [56]. Because unpublished reports or other grey literatures, such as theses, dissertations, and government and association reports, were excluded in this review, these programs were not included. I acknowledge this as a limitation of this review. Overwhelmingly, programs reviewed in this study reported positive outcomes. These positive outcomes warrant some caution in interpretation. It is conjectured that there is a bias in terms of studies reporting positive results, suggesting that an overrepresentation may occur as researchers are hesitant to publish negative or null findings. This study thus echoes past calls for publishing null and negative findings [14].

Funding: This research received no external funding.

Conflicts of Interest: The author declares no conflict of interest.

\section{References}

1. Harrison, N.; Tennent, C.; Vass, G.; Guenther, J.; Lowe, K.; Moodie, N. Curriculum and learning in aboriginal and Torres Strait Islander education: A systematic review. Aust. Educ. Res. 2019, 46, 233-251. [CrossRef]

2. Miller, J.; Armour, D. Supporting successful outcomes in mathematics for Aboriginal and Torres Strait Islander students: A systematic review. Asia-Pac. J. Teach. Educ. 2021, 49, 61-77. [CrossRef]

3. Castagno, A.E.; Brayboy, B.M.J. Culturally responsive schooling for Indigenous youth: A review of the literature. Rev. Educ. Res. 2008, 78, 941-993. [CrossRef]

4. Kim, M. Indigenous knowledge in Canadian science curricula: Cases from western Canada. Cult. Stud. Sci. Educ. 2017, 12, 605-613. [CrossRef]

5. Vass, G.; Lowe, K.; Burgess, C.; Harrison, N.; Moodie, N. The possibilities and practicalities of professional learning in support of Indigenous student experiences in schooling: A systematic review. Aust. Educ. Res. 2019, 46, 341-361. [CrossRef]

6. Sánchez Tapia, I.; Krajcik, J.; Reiser, B. “We do not know what is the real story anymore”: Curricular contextualization principles that support indigenous students in understanding natural selection. J. Res. Sci. Teach. 2018, 55, 348-376. [CrossRef]

7. Mack, E.; Augare, H.; Different Cloud-Jones, L.; Davíd, D.; Quiver Gaddie, H.; Honey, R.E.; Kawagley, A.O.; Little PlumeWeatherwax, M.; Lone Fight, L.; Meier, G.; et al. Effective practices for creating transformative informal science education programs grounded in Native ways of knowing. Cult. Stud. Sci. Educ. 2012, 7, 49-70. [CrossRef]

8. Brown, J.C. A metasynthesis of the complementarity of culturally responsive and inquiry-based science education in K-12 settings: Implications for advancing equitable science teaching and learning. J. Res. Sci. Teach. 2017, 54, 1143-1173. [CrossRef]

9. Kim, E.-J.A.; Asghar, A.; Jordan, S. A critical review of traditional ecological knowledge (TEK) in science education. Can. J. Sci. Math. Technol. Educ. 2017, 17, 258-270. [CrossRef]

10. Gillan, K.; Mellor, S.; Krakouer, J. The Case for Urgency: Advocating for Indigenous Voice in Education; ACER Press: Melbourne, Australia, 2017.

11. Page, M.J.; McKenzie, J.E.; Bossuyt, P.M.; Boutron, I.; Hoffmann, T.C.; Mulrow, C.D.; Shamseer, L.; Tetzlaff, J.M.; Akl, E.A.; Brennan, S.E.; et al. The PRISMA 2020 statement: An updated guideline for reporting systematic reviews. BMJ 2021, 372, n71. [CrossRef]

12. Cooper, H.M. Research Synthesis and Meta-Analysis: A Step-by-Step Approach, 4th ed.; Sage: Thousand Oaks, CA, USA, 2010.

13. Gough, D.; Oliver, S.; Thomas, J. An Introduction to Systematic Reviews, 2nd ed.; Sage: Thousand Oaks, CA, USA, 2017.

14. Ardoin, N.M.; Bowers, A.W. Early childhood environmental education: A systematic review of the research literature. Educ. Res. Rev. 2020, 31, 100353. [CrossRef]

15. Saldaña, J. The Coding Manual for Qualitative Researchers, 3rd ed.; Sage: Thousand Oaks, CA, USA, 2016.

16. Charmaz, K. Constructing Grounded Theory, 2nd ed.; Sage: Thousand Oaks, CA, USA, 2014.

17. Corbin, J.; Strauss, A. Basics of Qualitative Research: Techniques and Procedures for Developing Grounded Theory, 4th ed.; Sage: Thousand Oaks, CA, USA, 2014.

18. Barajas-López, F; Bang, M. Indigenous making and sharing: Claywork in an Indigenous STEAM program. Equity Excell. Educ. 2018, 51, 7-20. [CrossRef]

19. Kellogg, J.; Plundrich, N.J.; Lila, M.A. Engaging American Indian/Alaska Native (AI/AN) students with participatory bioexploration assays. NACTA J. 2016, 60, 42-50.

20. Tzou, C.; Suárez, E.; Bell, P.; LaBonte, D.; Starks, E.; Bang, M. Storywork in STEM-art: Making, materiality and robotics within everyday acts of Indigenous presence and resurgence. Cogn. Instr. 2019, 37, 306-326. [CrossRef] 
21. Eglash, R.; Lachney, M.; Babbitt, W.; Bennett, A.; Reinhardt, M.; Davis, J. Decolonizing education with Anishinaabe arcs: Generative STEM as a path to Indigenous futurity. Educ. Technol. Res. Dev. 2020, 68, 1569-1593. [CrossRef]

22. Pugh, P.; McGinty, M.; Bang, M. Relational epistemologies in land-based learning environments: Reasoning about ecological systems and spatial indexing in motion. Cult. Stud. Sci. Educ. 2019, 14, 425-448. [CrossRef]

23. Karagatzides, J.D.; Kozlovic, D.R.; De Iuliis, G.; Liberda, E.N.; General, Z.; Liedtke, J.; McCarthy, D.D.; Gomez, N.; Metatawabin, D.; Tsuji, L.J.S. Youth environmental science outreach in the Mushkegowuk territory of subarctic Ontario, Canada. Appl. Environ. Educ. Commun. 2011, 10, 201-210. [CrossRef]

24. Dublin, R.; Sigman, M.; Anderson, A.; Barnhardt, R.; Topkok, S.A. COSEE-AK ocean science fairs: A science fair model that grounds student projects in both Western science and traditional native knowledge. J. Geosci. Educ. 2014, 62, 166-176. [CrossRef]

25. Guzey, S.S.; Nyachwaya, J.; Moore, T.J.; Roehrig, G.H. Gaa-Noodin-Oke (alternative energy/wind power): A curriculum implementation on the white earth reservation. J. STEM Educ. 2014, 15, 5-13.

26. Ricci, J.L.; Riggs, E.M. Making a connection to field geoscience for Native American youth through culture, nature, and community. J. Geosci. Educ. 2019, 67, 487-504. [CrossRef]

27. Cheeptham, N.; Mahara, S.; Antoine, M.; Insuk, C.; Loy, K. Aboriginal youth summer camp in science and health science: A Western Canadian University review of 10 years of successes and learning. Int. J. Sci. Educ. 2020, 10, 204-216. [CrossRef]

28. Shortland, L.R.; Locke, T. The tomato pip's story: Creative narratives as bridging cultural and science discourses for Indigenous students. Aust. J. Indig. Educ. 2018, 47, 171-184. [CrossRef]

29. Lee, H.; Yen, C.-F.; Aikenhead, G.S. Indigenous elementary students' science instruction in Taiwan: Indigenous knowledge and Western science. Res. Sci. Educ. 2012, 42, 1183-1199. [CrossRef]

30. Rioux, J.; Ewing, B.; Cooper, T.J. Embedding Aboriginal perspectives and knowledge in the biology curriculum: The little porky. Aust. J. Indig. Educ. 2018, 47, 158-170. [CrossRef]

31. Rioux, J.; Ewing, B.; Cooper, T. Two-way conflation of home and school realities. Aust. Aborig. Stud. 2018, 1, 57-71.

32. Hackling, M.; Byrne, M.; Gower, G.; Anderson, K. A pedagogical model for engaging Aboriginal children with science learning. Teach. Sci. 2015, 61, 27-39.

33. Chiang, C.-L.; Lee, H. Crossing the gap between Indigenous worldview and Western science: Millet festival as a bridge in the teaching module. J. Educ. Train. Stud. 2015, 3, 90-100. [CrossRef]

34. Anthony-Stevens, V.; Mahfouz, J.; Bisbee, Y. Indigenous teacher education is nation building: Reflections of capacity building and capacity strengthening in Idaho. J. Sch. Leadersh. 2020, 30, 541-564. [CrossRef]

35. Miller, B.G.; Roehrig, G. Indigenous cultural contexts for STEM experiences: Snow snakes' impact on students and the community. Cult. Stud. Sci. Educ. 2018, 13, 31-58. [CrossRef]

36. Riffel, A.D. An insight into a school's readiness to implement a CAPS related Indigenous knowledge curriculum for meteorological sciences. Univers. J. Educ. Res. 2015, 3, 906-916. [CrossRef]

37. Upadhyay, B.; Atwood, E.; Tharu, B. Actions for sociopolitical consciousness in a high school science class: A case study of ninth grade class with predominantly Indigenous Students. J. Res. Sci. Teach. 2020, 57, 1119-1147. [CrossRef]

38. Dalbotten, D.; Ito, E.; Myrbo, A.; Pellerin, H.; Greensky, L.; Howes, T.; Wold, A.; Breckenridge, R.; Drake, C.; Bucar, L.; et al. NSF-OEDG Manoomin science camp project: A model for engaging American Indian students in science, technology, engineering, and mathematics. J. Geosci. Educ. 2014, 62, 227-243. [CrossRef]

39. Kelly, R.; Erduran, S. Understanding aims and values of science: Developments in the junior cycle specifications on nature of science and pre-service science teachers' views in Ireland. Ir. Educ. Stud. 2019, 38, 43-70. [CrossRef]

40. Fakoyede, S.J.; Otulaja, F.S. Beads and beadwork as cultural artifacts used in mediating learners' agentic constructs in science classrooms: A case for place-based learning. Cult. Stud. Sci. Educ. 2020, 15, 193-210. [CrossRef]

41. Bell, P.; Lewenstein, B.; Shouse, A.W.; Feder, M.A. Learning Science in Informal Environments: People, Places and Pursuits; The National Academies Press: Washington, DC, USA, 2009.

42. Ogawa, M. Science education in a multiscience perspective. Sci. Educ. 1995, 79, 583-593. [CrossRef]

43. Wood, A.; Lewthwaite, B. Māori science education in Aotearoa New Zealand. Cult. Stud. Sci. Educ. 2008, 3, 625-662. [CrossRef]

44. Sabzalian, L. Indigenous Children's Survivance in Public Schools; Routledge: New York, NY, USA, 2019.

45. Cochran-Smith, M.; Davis, D.; Fries, K. Multicultural teacher education: Research, practice, and policy. In Handbook of Research on Multicultural Education; Banks, J.A., Banks, C.A.M.G., Eds.; Jossey-Bass: San Francisco, CA, USA, 2004; pp. $931-975$.

46. González, N.; Moll, L.C.; Amanti, C. Funds of Knowledge: Theorizing Practices in Households, Communities and Classrooms; Routledge: New York, NY, USA, 2005.

47. Ma Rhea, Z. Leading and Managing Indigenous Education in the Postcolonial World; Routledge: Abingdon, UK, 2015.

48. National Research Council. A Framework for K-12 Science Education: Practices, Crosscutting Concepts, and Core Ideas; National Academy Press: Washington, DC, USA, 2012.

49. Aikenhead, G.S. Students' ease in crossing cultural borders into school science. Sci. Educ. 2001, 85, 180-188. [CrossRef]

50. Lee, O. Teacher change in beliefs and practices in science and literacy instruction with English language learners. J. Res. Sci. Teach. 2004, 41, 65-93. [CrossRef]

51. Aikenhead, G.S. Towards a cultural view on quality science teaching. In The Professional Knowledge Base of Science Teaching; Corrigan, D., Dillon, J., Gunstone, R., Eds.; Springer: New York, NY, USA, 2011; pp. 7-23.

52. Cobern, W.; Aikenhead, G.S. Cultural Aspects of Learning Science; Western Michigan University Scholar Works: Chicago, IL, USA, 1997. 
53. Aikenhead, G. Integrating Western and Aboriginal sciences: Cross-cultural science teaching. Res. Sci. Educ. 2001, 31, 337-355. [CrossRef]

54. Meyer, X.; Crawford, B.A. Teaching science as a cultural way of knowing: Merging authentic inquiry, nature of science, and multicultural strategies. Cult. Stud. Sci. Educ. 2011, 6, 525-547. [CrossRef]

55. McKinley, E.; Waiti, P.M.; Bell, B. Language, culture and science education. Int. J. Sci. Educ. 1992, 14, 579-595. [CrossRef]

56. Wiseman, D.; Glanfield, F.; Borden, L. Indigenous and Non-Indigenous ways of knowing, being, and doing in science and mathematics: A knowledge synthesis in Canada, 2006-2017. In Proceedings of the Canadian Society for the Study of Education (CSSE) Conference, Edmonton, AB, Canada, 30 May-3 June 2021. 